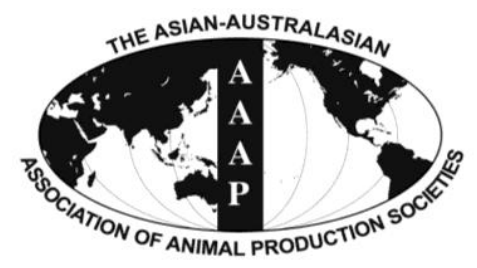

Asian-Aust. J. Anim. Sci.

Vol. 26, No. 4 : 558-563 April 2013

http://dx.doi.org/10.5713/ajas.2012.12566

www.ajas.info

pISSN 1011-2367 elSSN 1976-5517

\title{
Earlier Metabolizable Energy Intake Level Influences Heat Production during a Following 3-Day Fast in Laying Hens
}

\author{
D. Ning, Y. M. Guo*, Y. W. Wang and Y. Z. Peng \\ State Key lab of Animal Nutrition, College of Animal Science and Technology, \\ China Agricultural University, Beijing, 100193, China
}

\begin{abstract}
The present study was conducted to estimate energy requirements for maintenance in laying hens by using indirect calorimetry and energy balance. A total of 57628 -wk-old Nongda-3 laying hens with dwarf gene were randomly allocated into four ME intake levels $\left(86.57,124.45,166.63\right.$ and $197.20 \mathrm{kcal} / \mathrm{kg}$ body weight $(\mathrm{BW})^{0.75}$ per d) with four replicates each. After a $4 \mathrm{~d}$ adaptation period, 36 hens from one replicate were maintained in one of the two respiration chambers to measure the heat production (HP) for $3 \mathrm{~d}$ during the feeding period and subsequent $3 \mathrm{~d}$ fast. Metabolizable energy (ME) intake was partitioned between heat increment (HI), HP associated with activity, fasting HP (FHP) and retained energy (RE). The equilibrium FHP may provide an estimate of NE requirements for maintenance (NEm). Results showed that HP, HI and RE in the fed state increased with ME intake level ( $\mathrm{p}<0.05)$. Based on the regression of HP on ME intake, the estimated ME requirements for maintenance (MEm) was $113.09 \mathrm{kcal} / \mathrm{kg} \mathrm{BW}^{0.75}$ per d when ME intake equals HP. The FHP was decreased day by day with the lowest value on the third day of starvation. Except for lowest ME intake level, the FHP increased with ME intake level on the first day of starvation ( $\mathrm{p}<0.05)$. The FHP at the two higher ME intake levels were greater than that at the two lower ME intake levels $(\mathrm{p}<0.05)$ but no difference was found between the two lower ME intake levels. Linear regression of HP from the fed state to zero ME intake yielded a value of $71.02 \mathrm{kcal} / \mathrm{kg} \mathrm{BW}^{0.75}$ per d, which is higher than the extrapolated FHP at zero ME intake $\left(60.78,65.23\right.$ and $62.14 \mathrm{kcal} / \mathrm{kg} \mathrm{BW}{ }^{0.75}$ per $\mathrm{d}$ for the first, second and third day of fasting, respectively). Fasting time, lighting schedules, calculation methods and duration of adaptation of hens to changes in ME intake level should be properly established when using indirect calorimetry technique to estimate dietary NE content, MEm and NEm for laying hens. (Key Words: Net Energy, Metabolizable Energy, Laying Hens, Heat Production, Fasting, Indirect Calorimetry)
\end{abstract}

\section{INTRODUCTION}

Evaluation of energy content of feeds for laying hens is usually based on their metabolizable energy (ME) contents. As ME is not a predictor of how efficiently the bird then uses what is available (Macleod, 2000), net energy (NE) system has been proposed. When using a factorial analysis procedure to estimate $\mathrm{NE}$ values of diets, $\mathrm{NE}$ for maintenance (NEm) must be estimated (Noblet et al., 1994). The maintenance energy requirement is essentially an ATP requirement. The ME requirement for maintenance (MEm) was considered to be diet-dependent due to differences between nutrients, but NEm expressed as ATP needs in a non-producing state ought to be independent of nutritional level and related to animal state only. MEm for animals is usually estimated by establishing regression of heat

\footnotetext{
* Corresponding Author: Yuming Guo. Tel: +86-10-62733900, Fax: +86-10-62733900, E-mail: guoyum@ @au.edu.cn Submitted Oct. 8, 2012; Accepted Dec. 1, 2012; Revised Dec. 11, 2012
}

production (HP) on ME intake levels and extrapolation to the ME intake level at which it equals HP (Lange et al., 2006).

As NEm is difficult to measure directly, the equilibrium fasting heat production (FHP) is frequently used to estimate activity-free NEm (Birkett and de Lange, 2001a;b). Although the FHP can be measured during reasonably standardized conditions, it varies with the length of fasting period and previous nutrient-feeding level by Lange et al. (2006), which obtained three different extrapolated plateau HP following a $24 \mathrm{~h}$ fast increased with previous nutrientfeeding level in growing pigs.

Partitioning of ME can be determined by measuring HP, all ME not retained by the animal is lost as heat. According to Van Milgen et al. (1997), HP during feeding was partitioned into heat increment (HI, i.e. thermal effects of feeding), HP associated with activity $\left(\mathrm{HP}_{\mathrm{a}}\right)$ and FHP. There are few reports on energy metabolism and estimation of FHP for laying hens (Grimberger, 1970; Macleod and Jewitt, 
1988; Li et al., 1991). As proposed by Tess et al. (1984), it allowed for measurement of FHP based on the average HP for some time in fasting animals. Li et al. (1991) found that the HP associated with feeding had been eliminated after 22 $\mathrm{h}$ of fasting in laying hens. However, experimental methodology and variability among hens of different genotype may cause discrepancies on estimation of FHP.

The objective of the present study was to determine the effects of different amount of earlier ME intake on fasting $\mathrm{HP}$ and the main components of energy expenditure in laying hens using indirect calorimetry method. Linear regression was developed to analyze the relationship between the HP and ME intake in feeding and fast state.

\section{MATERIAL AND METHODS}

\section{Experimental design and diets}

The study protocol was approved and conducted in accordance with the Animal Ethics Committee guidelines of China Agricultural University.

A Total of 576 28-wk-old Nongda-3 laying hens with the dwarf gene were selected at approximately $1.12 \pm 0.04 \mathrm{~kg}$ body weight $(\mathrm{BW})$ and randomly allocated into one of four ME intake levels during four subsequent experimental periods. The feeding levels represented targeted daily $\mathrm{ME}$ intakes of $87,130,174,218 \mathrm{kcal} / \mathrm{kg} \mathrm{BW}^{0.75}$ per d, respectively. 144 laying hens were assigned to the same treatment with four replicates each, 36 hens per replicate. Experimental periods consisted of $4 \mathrm{~d}$ of adaptation (in a layer house) to experimental treatments followed by indirect calorimetry and N-balance measurements in two open-circuit respiration chambers. An adaptation period of 4 days was chosen to allow the size of visceral organ to adjust to the new ME intake. Since assignments of two replicates to the two respiration chambers were made each week, the measurement for each treatment lasted two weeks. Ingredients and nutrient composition of the experimental diets were shown in Table 1 . The corn and soybean mealbased diet (basal diet) was formulated to meet requirements of all experimental hens.

\section{Indirect calorimetry and nitrogen balance measurements}

Each respiration chamber was equipped with speciallymade upper and lower adjoining cages $(\mathrm{n}=12)$ measured $39 \times 37 \times 40 \mathrm{~cm}$ (width $\times$ depth $\times$ height) and housed three hens each, including four trays to collect the excreta of hens. The door of each respiration chambers contained a window that allowed for general observation of the birds. Temperature in the respiration chambers was set at $20 \pm 1{ }^{\circ} \mathrm{C}$. Relative humidity was $70 \%$.

36 hens from one replicate were maintained in one of the two respiration chambers for $7 \mathrm{~d}$ periods. In the
Table 1. The composition of basal diet and nutrients levels

\begin{tabular}{lc}
\hline Ingredient (\%) & Basal diet \\
\hline Corn & 63.09 \\
Soybean meal & 25.76 \\
Limestone & 7.99 \\
Dicalcium phosphate & 1.68 \\
Vitamin premix $^{1}$ & 0.02 \\
Mineral premix ${ }^{2}$ & 0.20 \\
DL-methionine & 0.14 \\
Threonine & 0.03 \\
Maifan stone & 0.63 \\
Choline chloride (50\%) & 0.12 \\
Salt & 0.30 \\
Antioxidant & 0.03 \\
Total & 100.00 \\
Nutrients levels & \\
Metaboliszable energy (Mcal/kg) & 2.63 \\
Crude protein $(\%)$ & 17.00 \\
Calcium (\%) & 3.50 \\
Available phosphorus (\%) & 0.40 \\
Lysine (\%) & 0.85 \\
Methionine (\%) & 0.40 \\
Threonine (\%) & 0.66 \\
Tryptophan (\%) & 0.19 \\
\hline Vin
\end{tabular}

${ }^{1}$ Vitamin premix provided per kilogram of diet: vitamin A, 12,500 IU; vitamin $\mathrm{D}_{3}, 2,500 \mathrm{IU}$; vitamin E, $30 \mathrm{IU}$; vitamin $\mathrm{K}_{3}, 2.65 \mathrm{mg}$; vitamin $\mathrm{B}_{1}$, $2 \mathrm{mg}$; vitamin $\mathrm{B}_{2}, 6 \mathrm{mg}$; vitamin $\mathrm{B}_{6}, 6 \mathrm{mg}$; vitamin $\mathrm{B}_{12}, 0.025 \mathrm{mg}$; biotin, $0.0325 \mathrm{mg}$; folic acid, $1.25 \mathrm{mg}$; pantothenic acid, $12 \mathrm{mg}$; niacin, $50 \mathrm{mg}$; ${ }^{2}$ Mineral premix provided per kilogram of diet: $\mathrm{Mn}, 100 \mathrm{mg}$; Fe, $80 \mathrm{mg}$; $\mathrm{Zn}, 75 \mathrm{mg}$; Cu, $8 \mathrm{mg}$; I, $0.35 \mathrm{mg}$; Se, $0.15 \mathrm{mg}$.

respiration chambers, hens were fed the basal diet daily according to four feeding levels at 8 a.m. Free access to water was allowed from nipple drinkers at all times. On days 1 to 4 , the lighting cycle was $16 \mathrm{~h}$ light: $8 \mathrm{~h}$ dark, lighting was switched on and off at 6 am and $10 \mathrm{pm}$. The first day served as adjustment to the new environment and was not considered in the final calculations. Measurements of $\mathrm{O}_{2}$ consumption and production of $\mathrm{CO}_{2}$ were made on days 2 to 4 in hens in the fed state. On $\mathrm{d} 5$ to $7, \mathrm{O}_{2}$ consumption and $\mathrm{CO}_{2}$ production were measured in fasting hens in the darkness. Hens were weighed before arranging into chambers and at the start and end of measuring fasting HP. Changes in gas concentrations by measuring $\mathrm{O}_{2}$ consumption and $\mathrm{CO}_{2}$ production were recorded at three minutes intervals and, combined with physical aspects of gas exchanges (changes in atmospheric pressure, relative humidity, gas extraction rates), were used to calculate daily total HP (van Milgen et al., 1997).

Heat production from hens was calculated without correction for $\mathrm{N}$ retention (Spratt et al., 1990) according to the equation proposed by Brouwer (1965): $\mathrm{HP}=$ $16.18 \times \mathrm{V}_{\mathrm{O} 2}+5.02 \times \mathrm{V}_{\mathrm{CO} 2}$, where $\mathrm{V}_{\mathrm{O} 2}$ and $\mathrm{V}_{\mathrm{CO} 2}$ are volume of gas. Since hens were fed diets daily by opening the door of chambers at 8 am, the unstable data from 8 am to 9 am was 
removed, and the daily total HP was calculated by extrapolation of the actual measurement made during approximately $23 \mathrm{~h}$ to a $24 \mathrm{~h}$ period. The respiration quotient (RQ) was determined as the volume of $\mathrm{CO}_{2}$ produced, divided by the volume of $\mathrm{O}_{2}$ consumed.

Total excreta was collected and frozen daily in every three adjoining cages on days 2 to 4 , so it contained four samples of excreta for each replicate. Samples of basal diet and excreta (free of feathers, scales, and cracked eggs) were dried in a forced-air oven at $65^{\circ} \mathrm{C}$ to constant weight and then ground to a fine particle size for subsequent measurement of total $\mathrm{N}$ and GE, measured using a Kjeldahl apparatus (KDY-9380, Shanghai, China) and an oxygen bomb calorimeter (WZR-I A, Changsha, China), respectively. Nitrogen retention $(\mathrm{RN})$ was calculated as the difference between $\mathrm{N}$ intake and $\mathrm{N}$ in the excreta. The AME values of experimental diets were calculated by subtracting GE excreted from GE intake and dividing this value by feed intake. Total retained energy (RE) was defined as the difference between ME intake and HP on a daily basis. Results concerning ME intake, HP, RE, HI and FHP were expressed as $\mathrm{kcal} / \mathrm{kg} \mathrm{BW}^{0.75} \cdot \mathrm{d}$.

\section{Statistical analysis and calculations}

Data were analyzed by one-way ANOVA of SPSS 17.0. The significance of differences among four treatment means was evaluated by Least Significant Difference (LSD) posthoc multiple comparisons test. Significance was $\mathrm{p}<0.05$ unless otherwise stated. Linear regression analyses were conducted to relate the various components of HP to ME intake.

\section{RESULTS}

\section{General observations}

Throughout the whole experiments periods, no laying hens were found in poor condition or dead. As shown in the Table 2, during d 2 to 5 in the respiration chambers, mean daily feed intake was 33.69, 48.30, 64.85 and $75.23 \mathrm{~g} / \mathrm{kg}$ $\mathrm{BW}^{0.75}$ per $\mathrm{d}(\mathrm{p}<0.001)$; the determined mean dietary AME contents were 2,596, 2,576, 2,569 and 2,619 kcal/kg ( $\mathrm{p}>0.05$ ), for the low, medium-low, medium-high and high $\mathrm{ME}$ intake level, respectively. The mean retained nitrogen increased with ME intake from $0.24 \mathrm{~g} / \mathrm{kg} \mathrm{BW}^{0.75}$ per $\mathrm{d}$ at the lowest $\mathrm{ME}$ intake to $0.93 \mathrm{~g} / \mathrm{kg} \mathrm{BW}^{0.75}$ per $\mathrm{d}$ at the highest ME intake.

\section{Components of energy expenditure}

The energy balance was measured during d 2 to 5 in the respiration chambers, mean observed daily ME intakes were $86.57,124.45,166.63$ and $197.20 \mathrm{kcal} / \mathrm{kg} \mathrm{BW}^{0.75}$ per $\mathrm{d}$ and similar to targeted ME intake levels. As shown in the Table 2 , total HP in hens in the fed state increased with ME intake level $(\mathrm{p}<0.001)$ from $106 \mathrm{kcal} / \mathrm{kg} \mathrm{BW}^{0.75}$ per $\mathrm{d}$ at the lowest ME intake to $146.93 \mathrm{kcal} / \mathrm{kg} \mathrm{BW}^{0.75}$ per $\mathrm{d}$ at the highest ME intake. The increase in ME intake was associated with higher RE $(\mathrm{p}<0.001)$ and HI $(\mathrm{p}<0.001)$. The HI contributed and $36.4 \%$ and $50.5 \%$ to HP in hens at the low and high ME intake levels, respectively. The total HP in hens at the lowest ME intake level exceeded their ME intake, leading to a negative value for RE. As the ME intake increased, the RQ in hens was significantly increased from 0.91 to 1.02 $(\mathrm{p}<0.001)$.

\section{HP and RQ in hens during fasting period}

As shown in the Table 3, the HP in fasting hens decreased day by day for the four ME intake levels. During days 1 to 3 of starvation, the fasting HP in hens for the two higher ME intake level were greater than that for the two lower ME intake level $(\mathrm{p}<0.05)$. However, there was no difference on daily HP in fasting hens between the low and medium-low intake level. No difference on HP in hens both

Table 2. Components of energy expenditure in laying hens at four different metabolisable energy intake levels (Mean values with standard errors of the treatment mean for four replicates per ME intake)

\begin{tabular}{|c|c|c|c|c|c|c|}
\hline \multirow{2}{*}{ Item } & \multicolumn{4}{|c|}{ ME intake levels } & \multirow{2}{*}{ SEM } & \multirow{2}{*}{ p-value } \\
\hline & Low & Medium-low & Medium-high & High & & \\
\hline Average $\mathrm{BW}^{1}(\mathrm{~kg})$ & 1.13 & 1.11 & 1.15 & 1.12 & 0.012 & 0.680 \\
\hline Feed intake $\left(\mathrm{g} / \mathrm{kg} \mathrm{BW}^{0.75}\right.$ per d) & $33.69^{\mathrm{d}}$ & $48.30^{c}$ & $64.85^{\mathrm{b}}$ & $75.23^{\mathrm{a}}$ & 2.892 & $<0.001$ \\
\hline $\mathrm{RN}^{1}\left(\mathrm{~g} / \mathrm{kg} \mathrm{BW}^{0.75}\right.$ per d) & $0.24^{\mathrm{d}}$ & $0.49^{\mathrm{c}}$ & $0.73^{\mathrm{b}}$ & $0.93^{\mathrm{a}}$ & 0.049 & $<0.001$ \\
\hline AME (kcal/kg) & 2,596 & 2,576 & 2,569 & 2,619 & 7.932 & 0.079 \\
\hline \multicolumn{7}{|l|}{ Energy balance } \\
\hline ME intake $\left(\mathrm{kcal} / \mathrm{kg} \mathrm{BW}^{0.75}\right.$ per d) & $86.57^{\mathrm{d}}$ & $124.45^{\mathrm{c}}$ & $166.62^{\mathrm{b}}$ & $197.20^{\mathrm{a}}$ & 7.713 & $<0.001$ \\
\hline $\mathrm{RE}^{1}\left(\mathrm{kcal} / \mathrm{kg} \mathrm{BW} \mathrm{B}^{0.75}\right.$ per $\left.\mathrm{d}\right)$ & $-19.87^{b}$ & $11.43^{\mathrm{b}}$ & $35.11^{\mathrm{a}}$ & $51.27^{\mathrm{a}}$ & 7.071 & $<0.001$ \\
\hline $\mathrm{HP}^{1}\left(\mathrm{kcal} / \mathrm{kg} \mathrm{BW}^{0.75}\right.$ per d) & $106.46^{\mathrm{c}}$ & $113.02^{\mathrm{c}}$ & $131.51^{\mathrm{b}}$ & $146.93^{\mathrm{a}}$ & 4.185 & $<0.001$ \\
\hline $\mathrm{HI}^{2}\left(\mathrm{kcal} / \mathrm{kg} \mathrm{BW} \mathrm{C}^{0.75}\right.$ per $\left.\mathrm{d}\right)$ & $38.79^{\mathrm{c}}$ & $46.06^{\mathrm{b}}$ & $60.05^{\mathrm{a}}$ & $74.16^{\mathrm{a}}$ & 3.549 & $<0.001$ \\
\hline $\mathrm{RQ}^{1}$ (fed state) & $0.91^{\mathrm{d}}$ & $0.95^{\mathrm{c}}$ & $0.98^{\mathrm{b}}$ & $1.02^{\mathrm{a}}$ & 0.013 & $<0.001$ \\
\hline
\end{tabular}

a, b, c, d Means within a row lacking a common superscript differ significantly $(\mathrm{p}<0.05)$.

${ }^{1} \mathrm{BW}=$ Body weight; RN = Retained nitrogen; RE = Retained energy; HP = Heat production of feeding; RQ = Respiratory quotient.

${ }^{2} \mathrm{HI}=$ Heat increment (including HP associated with activity), calculated as the difference between HP of feeding and fasting HP on the third day of starvation. 
on the d 2 and $\mathrm{d} 3$ of fasting were found between the medium-high and high intake level. The RQ was not influenced by ME intake level during days 1 to 3 of fasting.

There was a strong linear relationship between total HP in the fed state and ME intake, observations from the present study may be used to estimate the value of MEm and extrapolated $\mathrm{HP}$ at zero $\mathrm{ME}$ intake $\left(\mathrm{HP}_{0}\right.$, Figure 1$)$. Based on the linear regression analyses, $\mathrm{MEm}$ and $\mathrm{HP}_{0}$ was estimated to be 113.09 and $71.02 \mathrm{kcal} / \mathrm{kg} \mathrm{BW}^{0.75}$ per $\mathrm{d}$ for laying hens (Figure 1), extrapolated fasting HP in hens at zero ME intake on d 1, 2 and 3 of starvation was 60.78 , 65.23 and $62.14 \mathrm{kcal} / \mathrm{kg} \mathrm{BW}^{0.75}$ per d, respectively (Figure $1)$.

\section{DISCUSSION}

Effects of different ME intake levels on components of energy expenditure

The increase in feed intake was associated with higher energy and nitrogen retention in the present study, similar results were obtained for growing broiler (Macleod, 1990) and pigs (Lange et al., 2006). Daily intake of ME in hens in the fed state was more than $124.45 \mathrm{kcal} / \mathrm{kgW}^{0.75}$ per $\mathrm{d}$ except for the lowest ME intake level, which is sufficient to cover the ME requirements for maintenance. The RE contained both body energy and egg energy. As the ME intake decreased, the RE in hens at the lowest ME intake level reached a negative value, and the RQ of hens dropped from 1.02 at the highest ME intake to 0.91 at the lowest ME intake, indicating that hens at the lowest ME intake couldn't meet their MEm requirement and then used body energy for egg production (Spratt et al., 1990).

Across treatments in the present study, the HI in hens varied between $36.0 \%$ and $37.6 \%$ of ME intake when ME intake for hens exceeded their MEm $(44.8 \%$ for hens at the lowest ME intake), suggesting that ME intake level exerts little influence on the efficiency of deriving available energy from ME intake. However, Li et al. (1991) found that HP in laying hens associated with feeding was $16 \%$ of ME intake, which was lower than the value of present study for the reason that the HI contained the HP associated with activity in the present study.

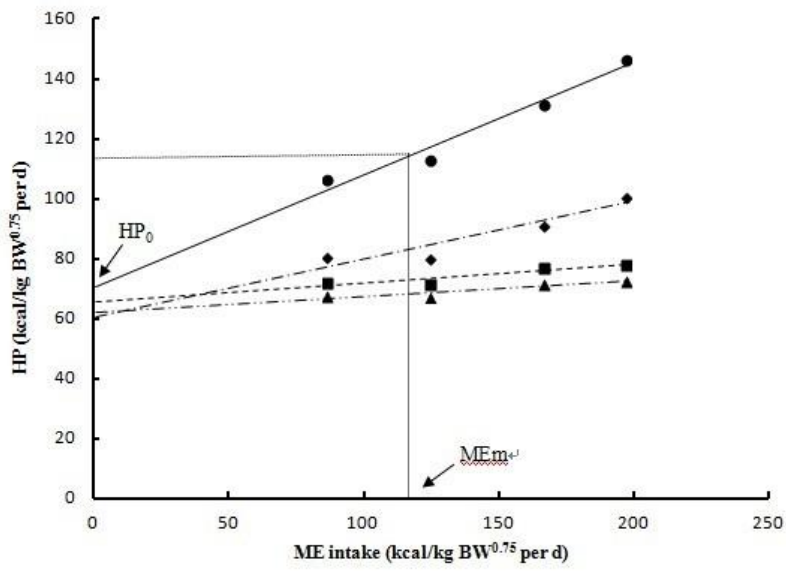

Figure 1. Total heat production (HP, $\bullet$ ) and fasting HP (d 1, $\bullet$; $2, \mathbf{m} ; \mathrm{d} 3, \mathbf{\Delta})$ in laying hens at four ME intake levels, as well as extrapolated $\mathrm{HP}$ at zero ME intake $\left(\mathrm{HP}_{0}\right)$ and estimated maintenance ME requirements (MEm, where ME intake equals $\mathrm{HP}, 113.09 \mathrm{kcal} / \mathrm{kg} \mathrm{BW}^{0.75}$ per d) based on linear regression analysis. Values are means. Total $\mathrm{HP}=71.02+0.372 \mathrm{ME}$ intake $\left(\mathrm{R}^{2}=0.9627\right)$; fasting HP $(\mathrm{d} 1)=60.78+0.1906 \mathrm{ME}$ intake $\left(\mathrm{R}^{2}=\right.$ $0.8662)$; fasting HP (d 2) $=65.23+0.0645 \mathrm{ME}$ intake $\left(\mathrm{R}^{2}=\right.$ $0.8215)$; fasting HP (d 3) $=62.14+0.0526 \mathrm{ME}$ intake $\left(\mathrm{R}^{2}=\right.$ $0.8194)$.

Light can stimulate physical activity of laying hens. In the present study, a pronounced diurnal rhythm in HP in the fed state was observed, which agreed with the findings of Sarmiento-Franco et al. (2000) and Li et al. (1992). Li et al. (1992) reported that HP declined with decreasing light intensity in laying hens. These effects were considered to result from changes in physical activity. Considering the effects of light on HP in hens, the lighting time should be strictly controlled.

\section{Effects of different ME intake levels on HP and RQ during fasting period}

In the present study, starvation markedly reduced the HP in laying hens compared with that in the fed state. As the fasting time prolonging, the fasting HP was decreased with the lowest value on the third day of starvation in each treatment, indicating that much little HP come from thermal effects of feed. However, no difference was found on

Table 3. Effect of ME intake levels on heat production (HP) and respiration quotient (RQ) in laying hens at different fasting time

\begin{tabular}{|c|c|c|c|c|c|c|c|}
\hline \multirow{2}{*}{ Item } & \multirow{2}{*}{ Fasting time } & \multicolumn{4}{|c|}{ ME intake levels } & \multirow{2}{*}{ SEM } & \multirow{2}{*}{ p-value } \\
\hline & & Low & Medium-low & Medium-high & High & & \\
\hline \multirow{3}{*}{$\begin{array}{l}\mathrm{HP} \\
\left(\mathrm{kcal} / \mathrm{kg} \mathrm{BW}^{0.75} \text { per d) }\right.\end{array}$} & Day 1 & $80.61^{\mathrm{c}}$ & $79.99^{c}$ & $91.22^{\mathrm{b}}$ & $100.86^{\mathrm{a}}$ & 2.634 & $<0.001$ \\
\hline & Day 2 & $71.97^{\mathrm{b}}$ & $71.16^{\mathrm{b}}$ & $76.74^{\mathrm{a}}$ & $78.10^{\mathrm{a}}$ & 0.982 & $<0.001$ \\
\hline & Day 3 & $67.67^{\mathrm{b}}$ & $66.96^{\mathrm{b}}$ & $71.46^{\mathrm{a}}$ & $72.69^{\mathrm{a}}$ & 0.814 & 0.003 \\
\hline \multirow[t]{3}{*}{ RQ } & Day 1 & 0.78 & 0.78 & 0.79 & 0.81 & 0.005 & 0.211 \\
\hline & Day 2 & 0.79 & 0.79 & 0.79 & 0.79 & 0.003 & 0.975 \\
\hline & Day 3 & 0.79 & 0.79 & 0.79 & 0.79 & 0.003 & 0.804 \\
\hline
\end{tabular}

\footnotetext{
a, b, c, d Means within a row lacking a common superscript differ significantly $(\mathrm{p}<0.05)$.
} 
fasting HP in hens between the low and medium-low intake level, and the fasting HP in hens at the two lower ME intake levels were significantly decreased than that at the two higher ME intake levels on both the second and third day of starvation, indicating that the HP on the third day of starvation at the low or medium-low intake level was stable and can be used to estimate plateau FHP.

Starvation can affect the oxidation pattern by reducing protein oxidation and shifting from carbohydrate to fat oxidation (Chwalibog et al., 2004). The fasting RQ was not influenced by ME intake level in the present study, but it was decreased from about 0.91 to 1.02 during free feeding to about 0.79 ( 0.78 vs 0.81$)$ during the $3 \mathrm{~d}$ of starvation, indicating that hens during starvation mobilized some body fat stores to sustain energy metabolism (Brouwer, 1965).

\section{Estimates of maintenance energy requirement}

Based on the similar method of present study, Macleod and Jewitt (1988) estimated the MEm in laying hens by using regression of a range of energy retentions on energy intakes followed by interpolation of zero energy retention, and found that this method didn't underestimate the value of MEm for laying hens. The estimate of MEm (113.09 $\mathrm{kcal} / \mathrm{kg} \mathrm{BW}^{0.75}$ per d) for laying hens in the present study is within range of estimates of MEm for birds of different genotype, for example, $136.0 \mathrm{kcal} / \mathrm{kgW}^{0.75}$ per $\mathrm{d}$ for laying hens (Li et al., 1991), $119.8 \mathrm{kcal} / \mathrm{kgW}^{0.75}$ per $\mathrm{d}$ for Rhode Island Red hens (Jadhao et al., 1999), 112 to $158 \mathrm{kcal} / \mathrm{kg}$ $\mathrm{BW}^{0.75} \cdot \mathrm{d}$ for broilers (Sakomura et al., 2005a) and 93 to 139 $\mathrm{kcal} / \mathrm{kg} \mathrm{BW} \mathrm{BW}^{0.75} \cdot \mathrm{d}$ for Lohmann hens (Sakomura et al., 2005b) under different temperatures, the latter three of which were based on the method of comparative slaughter technique. Except for the experimental methodology and ambient temperature, rearing system may also contribute to variation in estimates of MEm due to the energy expenditure for physical activity (Carlos Bôa-Viagem Rabello and de Resende, 2004).

The duration of adaptation of hens to changes in ME intake level before measuring HP should be considered carefully, especially when dietary NE contents were calculated as the sum of RE and estimated $\mathrm{HP}_{0}$ (Noblet et al., 1994; Birkett and de Lange, 2001b). It is important to determine how long laying hens should be fed when using regression analyses to estimate $\mathrm{MEm}$ and $\mathrm{HP}_{0}$ from $\mathrm{HP}$ at various ME intake levels. Macleod and Jewitt (1988) found that the stability of HP and energy intake in laying hens was approached after $2 \mathrm{~d}$ of reduced energy intake. $4 \mathrm{~d}$ adaption to each ME intake level in the present study can make hens obtain stable HP in the fed state. However, Spratt et al. (1990), who used same regression method with Macleod and Jewitt (1988) and allowed $3 \mathrm{~d}$ for adjustment to diets when measuring HP following a reduction in ME intake, obtained a $23 \%$ higher estimate of $\mathrm{HP}_{0}\left(87.7 \mathrm{kcal} / \mathrm{kg} \mathrm{BW}^{0.75}\right.$ per d) as compared with the value of $71.02 \mathrm{kcal} / \mathrm{kg} \mathrm{BW}^{0.75}$ per d obtained in the present study.

Since estimation of $\mathrm{HP}_{0}$ requires measurements of $\mathrm{HP}$ at different ME intake levels, the equilibrium FHP in different groups of animals is frequently used to estimate NEm (Birkett and de Lange, 2001a;b). The asymptotic nocturnal HP after $24 \mathrm{~h}$ of starvation was used for estimation of plateau FHP by van Milgen et al. (1997), which may eliminate the potential bias from duration of fast. However, FHP can also be measured as average HP in fasting animals during night hours (Tess et al., 1984), which was similar with the present study but for the different fasting time. As mentioned above, the equilibrium FHP in laying hens may be estimated based on the HP on the third day of starvation at the low or medium-low intake level.

Macleod (1990) found that maintenance energy requirement and fasting $\mathrm{HP}$ in growing broiler were not affected by diet. However, the present results suggested that fasting HP was influenced by earlier ME intake level. Li et al. (1991) found that HP in laying hens after $46 \mathrm{~h}$ of diet deprivation did not differ from that after $22 \mathrm{~h}$ of deprivation, but the present findings failed to observe an equilibrium fasting HP on the third day of fasting across treatments. Chwalibog et al. (2004) found that pigs after $4 \mathrm{~d}$ of starvation still couldn't reach an equilibrium FHP, so it is difficult to assess how long animals should be starved before fasting HP will be not affected by earlier feeding level. It appears reasonable to adjust fasting HP for their ME intake level by extrapolation to zero ME intake. Linear regression analysis showed that extrapolated fasting $\mathrm{HP}$ at zero ME intake on d 1, 2 and 3 of starvation (60.78 vs 65.23 $\mathrm{kcal} / \mathrm{kg} \mathrm{BW}{ }^{0.75}$ per d) are numerically lower than $\mathrm{HP}_{0}$ (71.02 $\mathrm{kcal} / \mathrm{kg} \mathrm{BW}^{0.75}$ per $\mathrm{d}$ ), these differences were considered to result from changes in physical activity due to little effect of activity on fasting HP in the dark.

\section{CONCLUSIONS}

ME intake level influenced HP, HI, RE during fed state. The fasting HP was also affected by earlier ME intake level but no difference was found between the two lower intake levels. Linear regression of HP in the fed state to zero ME intake yielded a higher estimate of NEm of $71.02 \mathrm{kcal} / \mathrm{kg}$ $\mathrm{BW}^{0.75}$ per $\mathrm{d}$ in laying hens than the extrapolated fasting $\mathrm{HP}$ at zero ME intake on d 1, 2 and 3 of starvation (60.78 vs $65.23 \mathrm{kcal} / \mathrm{kg} \mathrm{BW}^{0.75}$ per $\left.\mathrm{d}\right)$. In addition, fasting time and duration of adaption of laying hens to changes in ME intake level should be considered carefully when estimating maintenance energy requirements.

\section{ACKNOWLEDGEMENTS}

We wish to thank Professor Xiaoming Zhang, Geoff 
Kirton and Meng Li at the Ruminant Metabolism Research Unit in China Agricultural University for their excellent technical assistance in this experiment.

\section{REFERENCES}

Birkett, S. and K. de Lange. 2001a. A computational framework for a nutrient flow representation of energy utilization by growing monogastric animals. Br. J. Nutr. 86:661-674.

Birkett, S. and K. de Lange. 2001b. Limitations of conventional models and a conceptual framework for a nutrient flow representation of energy utilization by animals. Br. J. Nutr. 86:647-659.

Brouwer, E. 1965. Report of sub-committee on constants and factors. In: Energy Metabolism: Proc. 3rd Symp. K. L. Blaxter, ed. EAAP Publ. No. 11. Academic Press, London, UK. pp. 441-443.

Carlos Bôa-Viagem, R., N. K. Sakomura, F. A. Longo and K. T. de Resende. 2004. Effect of the environmental temperature and rearing systems on metabolizable energy requirements for maintenance of broiler breeders hens. Rev. Bras. Zootec. 33:382-390.

Chwalibog, A., A. H. Tauson and G. Thorbek. 2004. Energy metabolism and substrate oxidation in pigs during feeding, starvation and re-feeding. J. Anim. Physiol. Anim. Nutr. (Berl) 88:101-112.

Grimberger, A. H. M. 1970. The energy requirements for maintenance and production of laying hen. Neth. J. Agric. Sci. 18:195-206.

Jadhao, S. B., C. M. Tiwari, Chandramoni and M. Y. Khan. 1999. Energy requirement of Rhode Island red hens for maintenance by slaughter technique. Asian-Aust. J. Anim. Sci. 12:10851089.

Lange, K. D., J. V. Milgen, J. Noblet, S. Dubois and S. Birkett. 2006. Previous feeding level influences plateau heat production following a $24 \mathrm{~h}$ fast in growing pigs. Br. J. Nutr. 95:1082-1087.

Li, Y. Z., T. Ito and S. Yamamoto. 1991. Use of limited daily access to food in measuring the heat production associated with food intake in laying hens. Br. Poult. Sci. 32:829-839.
Li, Y., T. Ito, M. Nishibori and S. Yamamoto. 1992. Effects of environmental temperature on heat production associated with food intake and on abdominal temperature in laying hens. Br. Poult. Sci. 33:113-122.

MacLeod, M. G. 1990. Energy and nitrogen intake, expenditure and retention at 20 degrees in growing fowl given diets with a wide range of energy and protein contents. Br. J. Nutr. 64:625637.

MacLeod, M. G. 2000. Modelling the utilization of dietary energy and amino acids by poultry. In: Feeding Systems and Feed Evaluation Models (Ed. M. K. Theodorou and J. France). CAB International. pp. 393-412.

MacLeod, M. G. and T. R. Jewitt. 1988. Maintenance energy requirements of laying hens: a comparison of measurements made by two methods based on indirect calorimetry. Br. Poult. Sci. 29:63-74.

Noblet, J., H. Fortune, X. S. Shi and S. Dubois. 1994. Prediction of net energy value of feeds for growing pigs. J. Anim. Sci. 72:344-354.

Sakomura, N. K., F. A. Longo, E. O. Oviedo-Rondon, C. BoaViagem and A. Ferraudo. 2005a. Modeling energy utilization and growth parameter description for broiler chickens. Poult. Sci. 84:1363-1369.

Sakomura, N. K., R. Basaglia, C. M. L. Sá-Fortes and J. B. K. Fernandes. 2005b. Model for metabolizable energy requirements of laying hens. Rev. Bras. Zootec. 34:575-583.

Sarmiento-Franco, L., M. G. Macleod and J. M. McNab. 2000. True metabolisable energy, heat increment and net energy values of two high fibre foodstuffs in cockerels. Br. Poult. Sci. 41:625-629.

Spratt, R. S., H. S. Bayley, B. W. McBride and S. Leeson. 1990. Energy metabolism of broiler breeder hens. 1. The partition of dietary energy intake. Poult. Sci. 69:1339-1347.

Tess, M. W., G. E. Dickerson, J. A. Nienaber and C. L. Ferrell. 1984. The effects of body composition on fasting heat production in pigs. J. Anim. Sci. 58:99-110.

van Milgen, J., J. Noblet, S. Dubois and J. F. Bernier. 1997. Dynamic aspects of oxygen consumption and carbon dioxide production in swine. Br. J. Nutr. 78:397-410. 